\title{
Results and recommendations from an intercomparison of six Hygroscopicity-TDMA systems
}

\author{
A. Massling ${ }^{1,}$, N. Niedermeier ${ }^{1}$, T. Hennig ${ }^{1,2}$, E. O. Fors ${ }^{3}$, E. Swietlicki ${ }^{3}$, M. Ehn ${ }^{4}$, K. Hämeri ${ }^{4}$, P. Villani ${ }^{5}$, P. Laj ${ }^{5}$, \\ N. Good $^{6}$, G. McFiggans ${ }^{6}$, and A. Wiedensohler ${ }^{1}$ \\ ${ }^{1}$ Leibniz Institute for Tropospheric Research, Leipzig, Germany \\ ${ }^{2}$ Stockholm University, Department of Applied Environmental Science, Stockholm, Sweden \\ ${ }^{3}$ Lund University, Department of Physics, Lund, Sweden \\ ${ }^{4}$ University of Helsinki, Department of Physics, Helsinki, Finland \\ ${ }^{5}$ Université Blaise Pascal, Laboratoire de Météorologie Physique, Clermont Ferrand, France \\ ${ }^{6}$ University of Manchester, Department of Atmospheric and Environmental Sciences, Manchester, UK \\ *now at: Aarhus University, National Environmental Research Institute, Department of Atmospheric Environment, \\ Roskilde, Denmark
}

Received: 6 October 2009 - Published in Atmos. Meas. Tech. Discuss.: 15 February 2010

Revised: 4 January 2011 - Accepted: 9 February 2011 - Published: 8 March 2011

\begin{abstract}
The performance of six custom-built Hygrocopicity-Tandem Differential Mobility Analyser (H-TDMA) systems was investigated in the frame of an international calibration and intercomparison workshop held in Leipzig, February 2006. The goal of the workshop was to harmonise HTDMA measurements and develop recommendations for atmospheric measurements and their data evaluation. The $\mathrm{H}$ TDMA systems were compared in terms of the sizing of dry particles, relative humidity (RH) uncertainty, and consistency in determination of number fractions of different hygroscopic particle groups. The experiments were performed in an air-conditioned laboratory using ammonium sulphate particles or an external mixture of ammonium sulphate and soot particles.

The sizing of dry particles of the six H-TDMA systems was within 0.2 to $4.2 \%$ of the selected particle diameter depending on investigated size and individual system. Measurements of ammonium sulphate aerosol found deviations equivalent to $4.5 \% \mathrm{RH}$ from the set point of $90 \% \mathrm{RH}$ compared to results from previous experiments in the literature. Evaluation of the number fraction of particles within the clearly separated growth factor modes of a laboratory generated externally mixed aerosol was done. The data from the H-TDMAs was analysed with a single fitting routine to investigate differences caused by the different data evaluation
\end{abstract}

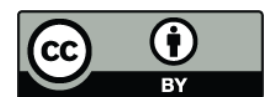

Correspondence to: A. Massling (anma@dmu.dk) procedures used for each H-TDMA. The differences between the H-TDMAs were reduced from $+12 /-13 \%$ to $+8 /-6 \%$ when the same analysis routine was applied. We conclude that a common data evaluation procedure to determine number fractions of externally mixed aerosols will improve the comparability of H-TDMA measurements.

It is recommended to ensure proper calibration of all flow, temperature and $\mathrm{RH}$ sensors in the systems. It is most important to thermally insulate the aerosol humidification unit and the second DMA and to monitor these temperatures to an accuracy of $0.2{ }^{\circ} \mathrm{C}$. For the correct determination of external mixtures, it is necessary to take into account size-dependent losses due to diffusion in the plumbing between the DMAs and in the aerosol humidification unit.

\section{Introduction}

Aerosol particles play a significant role in terms of their influence on regional and global climate by interacting with solar radiation (Ramanathan et al., 2001) and their ability to form cloud droplets (Kaufmann et al., 2002). Understanding the hygroscopic properties of aerosol particles is crucial for determining their impact on regional and global climate (IPCC, 2007). The particles' hygroscopicity is strongly linked to their ability to form cloud droplets. In addition to the particles' contribution to the direct and indirect effect, their presence in the atmosphere reduces visibility, which

Published by Copernicus Publications on behalf of the European Geosciences Union. 


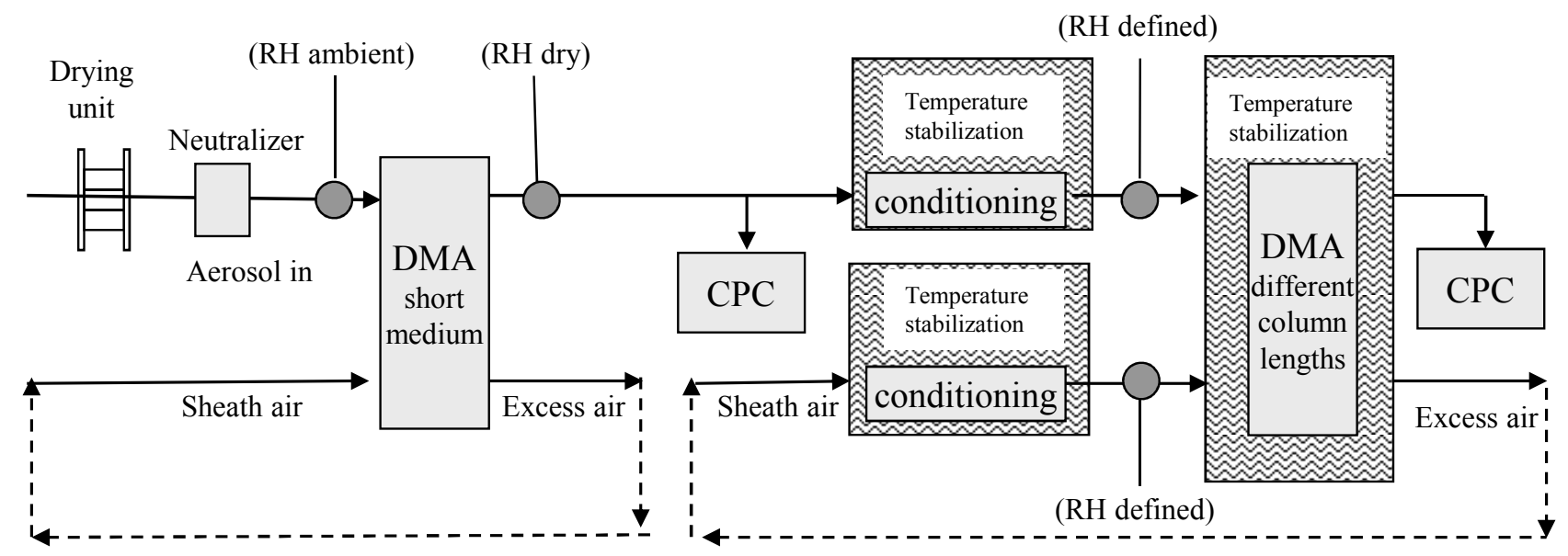

Fig. 1. Schematic picture of the custom-built H-TDMA systems used within this study. Systems showed varying technical details. The dotted lines show the possibility for a closed loop system realised by some of the used set ups. The sheath air of the second DMA can also be used for humidification of the aerosol sample air, which is not shown in the sketch, but realised for some of the used set ups.

is an important issue in highly polluted areas (Cheng et al., 2008). This effect increases with ascending ambient relative humidity in the atmosphere.

The H-TDMA (Hygroscopicity-Tandem Differential Mobility Analyser) system was first introduced by Liu et al. (1978). In the last three decades the technique has been established and used to measure size-resolved hygroscopic growth factors and mixing state of submicrometer particles with high temporal resolution in various atmospheric environments (e.g. Kandler and Schütz, 2007; Swietlicki et al., 2008). Until recently H-TDMA systems have not been commercially available, hence all existing systems have custom designs (Cubison et al., 2005; Hennig et al., 2005; Johnson et al., 2005; Massling et al., 2003; Rader and McMurry, 1986; Weingartner et al., 2002). In general, these systems have substantial differences in their design, data quality assurance and data evaluation procedures. Data evaluation procedures may differ in terms of the applied data analysis methods and the way they account for system-dependent calibrations (Cubison et al., 2005; Gysel et al., 2009; Stolzenburg and McMurry, 1988; Voutilainen et al., 2000).

In this study, six European H-TDMA systems were investigated in an international calibration and intercomparison workshop held at the Leibniz Institute for Tropospheric Research in Leipzig, Germany, in February 2006. This workshop was the first of three experimental H-TDMA intercomparisons.

The aim of this experimental study was to investigate the performance of the different systems. Specifically the H-TDMAs' ability to sizeselect particles, to determine the growth factor as a function of $\mathrm{RH}$, to operate at stable $\mathrm{RH}$ over time and to determine the number fraction of particles within specified growth factor ranges was assessed. In addition, a standard data evaluation procedure was applied to all raw data to intercompare the performance of the H-TDMA systems independently of the applied data evaluation procedure.

To the best of the authors' knowledge there is only one study stating a comparison between H-TDMA systems (Duplissy et al., 2009). In addition to the existing comparison study by Duplissy et al., the sizing uncertainties as function of particle dry size and the ability to determine the number fractions independently of the data evaluation routines were assessed. Of the six custom-built H-TDMA systems in this study, four were not part of the previous study.

Based on this study, a set of general recommendations to technically harmonise H-TDMA systems and to standardise procedures for data quality are proposed. Such recommendations are needed to assure the comparability of measured hygroscopic properties of submicrometer particles using $\mathrm{H}$ TDMA systems.

\section{Instruments and experimental set up}

An H-TDMA consists of two Differential Mobility Analysers (DMAs) in series with an aerosol humidifier between them. A schematic is given in Fig. 1. The first DMA selects a narrow particle size fraction from the aerosol (I). This fraction is then humidified in the aerosol conditioner to a welldefined relative humidity (II). The humidified size distribution is then determined by a size spectrometer (III) consisting of a second DMA in combination with a Condensation Particle Counter (CPC).

Custom-built H-TDMA systems can have significant differences in design. Systems compared in this study used various DMA designs, CPC types, flow schemes (separated sheath and excess air or closed loop), DMA 1 drying, DMA 2 humidification, $\mathrm{RH}$ measurements, $\mathrm{RH}$ regulation and temperature stabilization (of the humidifying section and of 
Table 1. Differences in technical details of operated H-TDMA systems during the comparison.

\begin{tabular}{ll}
\hline Technical detail & Differences in technical details \\
\hline DMA & Vienna type $(11,28 \mathrm{~cm})$, TSI type \\
CPC & Different models of TSI butanol based CPCs \\
Sheath air DMA 1/DMA 2 & Closed loop set up, Sheath and excess air separated \\
Sheath air DMA 1 drying & Silica gel dryers, Perma pure driers \\
Humidification section & Perma pure humidifiers (gas to gas and water to gas humidification) - mixing of wet and dry \\
& air flows, Gore tex tubing with temperature control for humidification. \\
Sample/sheath air humidification & Both sample and sheath air humidified to same RH, sample air RH slightly lower than sheath \\
& air RH \\
$T$ stabilization of humididfication section & None, Water bath, isolated box \\
RH measurement & Different models of capacitive sensors (Vaisala, Rotronic), Self-built sensors, Dew point \\
& mirrors \\
$T$ stabilization DMA 2 & No isolatiom, Armaflex isolation, Water isolation, Water bath, Temperature controlled water \\
& bath \\
\hline
\end{tabular}

Table 2. List of instruments operated during the different experiments.

\begin{tabular}{lllrrrrrr}
\hline Experiment Nr. & Aerosol & Objective & Sys. 1 & Sys. 2 & Sys. 3 & Sys. 4 & Sys. 5 & Sys. 6 \\
\hline 1 & AS & DMA sizing & X & X & X & X & X & X \\
2 & AS & RH uncertainty and stability & X & X & & & X & X \\
3 & AS & DRH deviation & X & X & & X & X & X \\
4 & AS + soot & Differentiation between two hygroscopic growth modes & X & X & & X & X & X \\
5 & AS + soot & Determination of number fractions & X & X & & & X & X \\
\hline
\end{tabular}

DMA 2). Table 1 gives an overview of differences in technical details of operated H-TDMA systems within this comparison. Detailed descriptions of the systems compared in this study can be found in the following publications (Cubison et al., 2005; Hämeri et al., 2000; Hennig et al., 2005; Massling et al., 2003; Villani et al., 2008; Zhou, 2001).

All instruments were placed in an air-conditioned laboratory operated at $T=22{ }^{\circ} \mathrm{C}$ and were connected to a mixing chamber. Five different experiments were carried out. For experiments 1, 2, and 3 ammonium sulphate particles were generated - concentration of $\left(\mathrm{NH}_{4}\right)_{2} \mathrm{SO}_{4}$ in water $0.1 \mathrm{~g} \mathrm{~L}^{-1}$ using an atomiser (TSI, Model 3076) and introduced to the mixing chamber. The mixing chamber consisted of a $0.75 \mathrm{~m} \times 0.75 \mathrm{~m} \times 0.75 \mathrm{~m}$ stainless steel box with a small blower inside to provide a homogeneously mixed aerosol. The flow from the atomiser of approximately $2 \mathrm{~L} \mathrm{~min}^{-1}$ was diluted by a dry, particle-free, oil-free air flow of approximately $4 \mathrm{~L} \mathrm{~min}^{-1}$. During experiment 4 and 5 , soot particles (Printex 85) were suspended in water and atomised using a second atomiser of the same model. The soot aerosol flow $\left(2 \mathrm{~L} \mathrm{~min}^{-1}\right)$ was added into the mixing chamber to provide an externally mixed aerosol together with the ammonium sulphate particles.
All systems measured simultaneously from the mixing chamber and were operated at the same dry sizes and set point RH. Data were obtained for the dry sizes $D p=30,50$, 70 , and $100 \mathrm{~nm}$ except for system 1 , that could not be operated at $D p=100 \mathrm{~nm}$ because it was designed to investigate ultrafine aerosol particles and therefore the upper size range was lower. The aerosol was dried only by systems' inbuilt drying sections before entering the first DMA. As listed in Table 2 not all instruments delivered data during all five experiments.

\section{Data evaluation}

It was found that the quality criteria used for the different H-TDMA systems and their retrieved data differed. Quality checks with regard to the stability in RH were made for each system, however flow rates and temperatures were not monitored by all of the systems.

Individual data evaluation procedures were used for each H-TDMA system due to different number and type of corrections applied to the retrieved humidified particle number size distributions from each single system. Differences may 

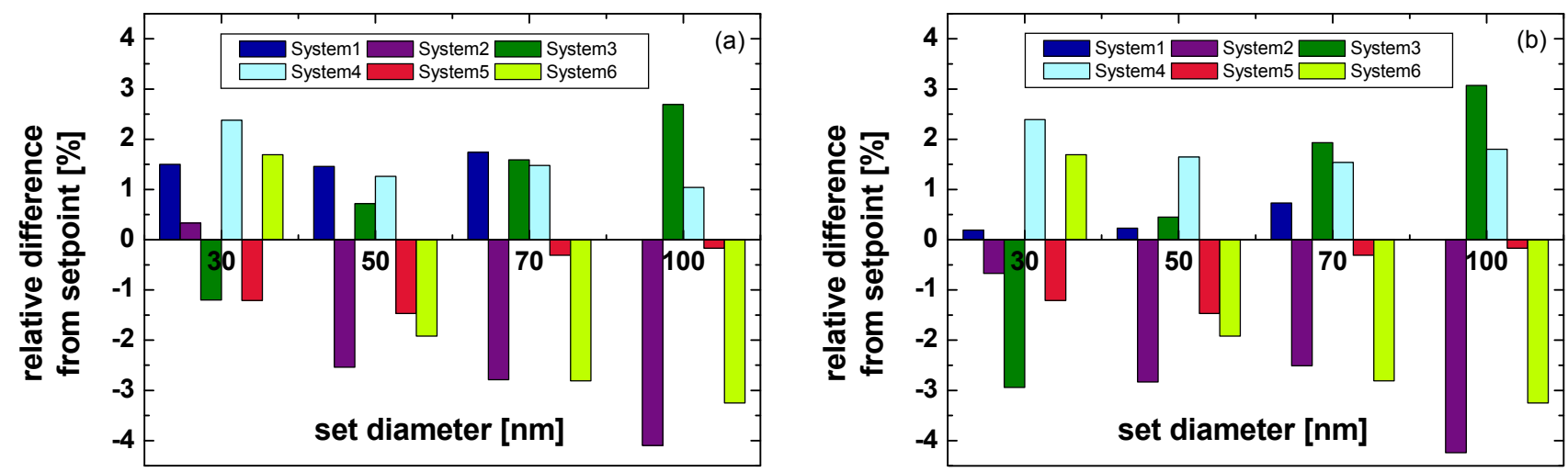

Fig. 2. (a) Externally and (b) internally evaluated growth factor difference for all systems at dry conditions.

occur in terms of the following corrections: CPC efficiency, diffusional particle losses in the DMA, system-dependent particle losses in the tubing, correction for the DMA sizing of dry particles and DMA transfer functions (experimentally derived or ideal).

Here, all individual data evaluation procedures took into account the effect of the DMA transfer function on the retrieved humidified particle number size distributions. Some of the individual data evaluation procedures used the experimentally derived transfer function of the DMAs and other procedures used the ideal transfer functions. All individual data evaluation procedures corrected for the DMA sizing of the dry particles. In the following description the individual data evaluation procedures will be labelled as external data evaluation procedures.

All raw data were post-processed the same way using a common data evaluation procedure. The common data evaluation procedure included the recalculation of the humidified particle number size distribution $(\mathrm{d} N / \mathrm{d} \log D p)$ without accounting for multi charging, neglecting diffusional losses in the DMA and CPC detection efficiencies. DMA 2 was assumed to have an ideal transfer function. This evaluation will be denoted as the internal data evaluation procedure.

In the present study the data were evaluated using both data evaluation procedures. In all but one of the evaluation procedures lognormal functions were fitted to the retrieved humidified particle number size distributions to obtain mean values of single particle modes and the number concentration assigned to those using individual programs. For the internal data evaluation procedure one and the same fitting routine was used.

\section{Results and recommendations}

All results shown in the following sections are based on mean values of the parameter in question of the respective experiment for the individual systems. Some systems were only operated for a certain part of the experiment. In addition, an evaluation with respect to time variability is presented.

\subsection{DMA sizing of dry particles}

To obtain exact hygroscopic growth factors at a chosen $\mathrm{RH}$ using the H-TDMA technique, it is most important that both DMAs select the same particle size at dry conditions when operated at the same size. The exact sizing of a DMA can differ from the set value because of several reasons. Some of these reasons are due to an incorrect calculation of the particle mobility where the ambient temperature and pressure in the DMA and the geometry of the DMA is used. Other reasons might be due to an inadequate operation of the system like sheath flow deviations from the set value, the relative humidity in the DMA or calibration of the high voltage power supply.

For H-TDMA systems, two DMAs are operated in series, and the above mentioned issues occur in both. This may lead to a shift between the selected particle sizes of both DMAs resulting in a growth factor not equal to unity under dry conditions, even though the particle diameter is not expected to change in the H-TDMA. Therefore, the size-dependent dry growth factors for the individual H-TDMA systems were measured.

The dry growth factors $G F_{\text {dry }}$ were derived by calculating the ratio of the derived diameter $D p_{\mathrm{DMA} 2}$ (dry conditions) of the particle number size distribution measured with DMA 2 and CPC 2 and the initial diameter $D p_{\text {DMA1 }}$ (dry conditions) set by DMA 1 following Eq. (1).

$G F_{\text {dry }}=\frac{D p_{\text {DMA2 }}(\mathrm{RH}<20 \%)}{D p_{\text {DMA1 }}(\mathrm{RH}<20 \%)}$.

During experiment 1 , the H-TDMA systems were operated under dry conditions and sampled pure ammonium sulphate particles, yielding the dry growth factor (ideally 1.0) for selected dry sizes of $D p=30,50,70$ and $100 \mathrm{~nm}$.

In Fig. $2 \mathrm{a}$ and $\mathrm{b}$, the results of this experiment are shown presenting the evaluation of both procedures (external and 
Table 3. Mean dry growth factors (DMA sizing of dry particles) (exp. 1), hygroscopic growth factors (exp. 2) \pm 1 std., deliquescence relative humidities (exp. 3) derived for ammonium sulphate particles based on internal and external data evaluation procedures and more hygroscopic number fractions derived for the externally mixed aerosol (exp. 5) $\pm 1 \mathrm{std}$.

\begin{tabular}{|c|c|c|c|c|c|c|c|c|c|c|c|c|c|}
\hline & $\begin{array}{r}\text { AS } \\
\text { from } \\
\text { literat. }\end{array}$ & $\begin{array}{r}\text { Sys. } 1 \\
\text { ext. } \\
\text { eval. }\end{array}$ & $\begin{array}{r}\text { Sys. } 1 \\
\text { int. } \\
\text { eval. }\end{array}$ & $\begin{array}{r}\text { Sys. } 2 \\
\text { ext. } \\
\text { eval. }\end{array}$ & $\begin{array}{r}\text { Sys. } 2 \\
\text { int. } \\
\text { eval. }\end{array}$ & $\begin{array}{r}\text { Sys. } 3 \\
\text { ext. } \\
\text { eval. }\end{array}$ & $\begin{array}{r}\text { Sys. } 3 \\
\text { int. } \\
\text { eval. }\end{array}$ & $\begin{array}{r}\text { Sys. } 4 \\
\text { ext. } \\
\text { eval. }\end{array}$ & $\begin{array}{r}\text { Sys. } 4 \\
\text { int. } \\
\text { eval. }\end{array}$ & $\begin{array}{r}\text { Sys. } 5 \\
\text { ext. } \\
\text { eval. }\end{array}$ & $\begin{array}{r}\text { Sys. } 5 \\
\text { int. } \\
\text { eval. }\end{array}$ & $\begin{array}{r}\text { Sys. } 6 \\
\text { ext. } \\
\text { eval. }\end{array}$ & $\begin{array}{r}\text { Sys. } 6 \\
\text { int. } \\
\text { eval. }\end{array}$ \\
\hline \multicolumn{14}{|c|}{ Experiment 1: DMA sizing } \\
\hline$D p=30 \mathrm{~nm}$ & 1.00 & 1.02 & 1.00 & 1.00 & 0.99 & 0.99 & 0.97 & 1.02 & 1.02 & 0.99 & 0.99 & 1.02 & 1.02 \\
\hline$D p=50 \mathrm{~nm}$ & 1.00 & 1.01 & 1.00 & 0.98 & 0.97 & 1.01 & 1.00 & 1.01 & 1.02 & 0.99 & 0.99 & 0.98 & 0.98 \\
\hline$D p=70 \mathrm{~nm}$ & 1.00 & 1.02 & 1.01 & 0.97 & 0.98 & 1.02 & 1.02 & 1.02 & 1.02 & 1.00 & 1.00 & 0.97 & 0.97 \\
\hline$D p=100 \mathrm{~nm}$ & 1.00 & - & - & 0.96 & 0.96 & 1.03 & 1.03 & 1.01 & 1.02 & 1.00 & 1.00 & 0.97 & 0.97 \\
\hline \multicolumn{14}{|c|}{ Experiment 2: RH uncertainty } \\
\hline$D p=30 \mathrm{~nm}$ & 1.61 & $\begin{array}{r}1.78 \\
\pm \\
0.04\end{array}$ & $\begin{array}{r}1.79 \\
\pm \\
0.04\end{array}$ & $\begin{array}{r}1.63 \\
\pm \\
0.04\end{array}$ & $\begin{array}{r}1.61 \\
\pm \\
0.02\end{array}$ & - & - & - & - & $\begin{array}{r}1.64 \\
\pm \\
0.05\end{array}$ & $\begin{array}{r}1.64 \\
\pm \\
0.05\end{array}$ & - & - \\
\hline$D p=50 \mathrm{~nm}$ & 1.66 & $\begin{array}{r}1.82 \\
\pm \\
0.04\end{array}$ & $\begin{array}{r}1.82 \\
\pm \\
0.05\end{array}$ & $\begin{array}{r}1.62 \\
\pm \\
0.04\end{array}$ & $\begin{array}{r}1.57 \\
\pm \\
0.02\end{array}$ & - & - & - & - & $\begin{array}{r}1.69 \\
\pm \\
0.07\end{array}$ & $\begin{array}{r}1.69 \\
\pm \\
0.07\end{array}$ & $\begin{array}{r}1.69 \\
\pm \\
0.00\end{array}$ & $\begin{array}{r}1.69 \\
\pm \\
0.00\end{array}$ \\
\hline$D p=70 \mathrm{~nm}$ & 1.68 & $\begin{array}{r}1.84 \\
\pm \\
0.05\end{array}$ & $\begin{array}{r}1.84 \\
\pm \\
0.05\end{array}$ & $\begin{array}{r}1.58 \\
\pm \\
0.04\end{array}$ & $\begin{array}{r}1.58 \\
\pm \\
0.01\end{array}$ & - & - & - & - & $\begin{array}{r}1.70 \\
\pm \\
0.07\end{array}$ & $\begin{array}{r}1.70 \\
\pm \\
0.07\end{array}$ & $\begin{array}{r}1.67 \\
\pm \\
0.00\end{array}$ & $\begin{array}{r}1.67 \\
\pm \\
0.00\end{array}$ \\
\hline$D p=100 \mathrm{~nm}$ & 1.70 & - & - & $\begin{array}{r}1.57 \\
\pm \\
0.02\end{array}$ & $\begin{array}{r}1.56 \\
\pm \\
0.01\end{array}$ & - & - & - & - & $\begin{array}{r}1.72 \\
\pm \\
0.08\end{array}$ & $\begin{array}{r}1.72 \\
\pm \\
0.08\end{array}$ & $\begin{array}{r}1.67 \\
\pm \\
0.00\end{array}$ & $\begin{array}{r}1.67 \\
\pm \\
0.00\end{array}$ \\
\hline \multicolumn{14}{|c|}{ Experiment 3: DRH deviation } \\
\hline $\mathrm{DRH}, D p=70 \mathrm{~nm}$ & 79.97 & 75.11 & 74.76 & 79.14 & 78.82 & - & - & 75.54 & 75.43 & 78.73 & 78.73 & 78.86 & 78.86 \\
\hline \multicolumn{14}{|c|}{ Experiment 5: Number fractions $50 \mathrm{~nm}(90 \%)$} \\
\hline $\begin{array}{l}\text { NF (more } \\
\text { hygroscopic } \\
\text { mode) }\end{array}$ & & $\begin{array}{r}0.49 \\
\pm \\
0.02\end{array}$ & $\begin{array}{r}0.48 \\
\pm \\
0.02\end{array}$ & $\begin{array}{r}0.41 \\
\pm \\
0.02\end{array}$ & $\begin{array}{r}0.50 \\
\pm \\
0.02\end{array}$ & - & - & 0.47 & $\begin{array}{l}0.49 \\
0.02\end{array}$ & $\begin{array}{r}0.49 \\
\pm \\
0.02\end{array}$ & $\begin{array}{r}0.49 \\
\pm \\
0.02\end{array}$ & $\begin{array}{r}0.43 \\
\pm\end{array}$ & $\begin{array}{r}0.43 \\
\pm\end{array}$ \\
\hline
\end{tabular}

internal data evaluation). For a better comparison, the relative difference in \% from the set value is plotted in Fig. 2a and $\mathrm{b}$ and the nominal values of $G F_{\text {dry }}$ are additionally listed in Table 3.

In general, shifts in sizing between the two DMAs of individual systems were between $0.2 \%$ and $4.2 \%$ depending on the investigated particle size. The external and internal data evaluations differed within $2 \%$ on an absolute scale and only in exceptional cases. This result shows that the application of external and internal data evaluation may lead to different results although these evaluations are based on one and the same raw data. For some set ups, relative shifts in the DMA sizing of dry particles increased or decreased slightly with increasing particle size. For other set ups the relative shift was nearly constant as a function of size. This implies that the reasons for the observed discrepancies varied from system to system. It is assumed that deviations in DMA sheath air flows caused the observed discrepancies at least for some of the systems. Statements on discrepancies due to the calibration of the high voltage power supply cannot be concluded here as those affect the DMA sizing of dry particles in general at smaller diameters than $D p=30 \mathrm{~nm}$. Insufficient drying by system inbuilt drying sections (e.g. silica gel columns, perma pure membranes) will also be excluded as ammonium sulphate particles deliquesce at 35-40\% RH and all systems were operated at a lower RH.

\section{Recommendations}

Shifts in sizing between the two DMAs of individual systems were up to about $4.2 \%$. It is therefore proposed that the dry growth factors for a system are determined by sampling ammonium sulphate particles (recommended as showing no shape factor) to determine any offset between DMA 1 and DMA 2 as a function of dry size. Dry scans should be performed regularly during field studies, at least once in a week. 

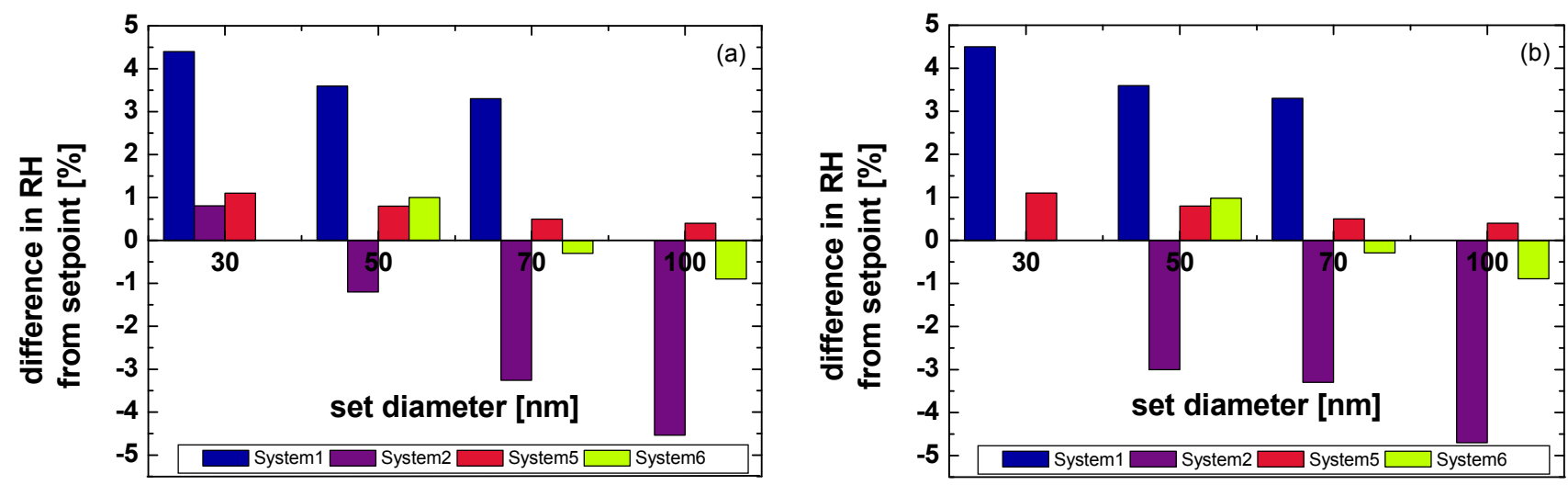

Fig. 3. (a) Externally and (b) internally evaluated RH difference for all systems and $D p=30,50,70$, and 100 nm measured at a set point of $\mathrm{RH}=90 \%$.

It is also recommended that the same dry sizes are used for the DMA offset calibration as in the experimental study. The dry growth factor correction (see Eq. 1) should then be applied to all measured data. This recommendation is consistent with the suggestions reported by Duplissy et al. (2009). If the dry scans show deviations of more than $2 \%$ in size, it is recommended the system is checked as some insufficient calibration of the system is expected.

In principle, high voltage power supplies should be calibrated before set up of the instrument, especially for low voltages $(<100 \mathrm{~V})$. The calibration of the power supplies should be done after a warm up period of at least one hour. An exact calibration of the flow sensors may avoid larger uncertainties in the DMA sizing. Frequent verification of the sheath and aerosol flow rates and the certainty of the corresponding sensors that are used to control the flows is recommended. The sizing of individual DMAs should be verified by Polystyrene Latex (PSL) spheres of known size in the operating size range of the system before the experiment. If possible, the real experimentally derived DMA transfer function should be used in the data evaluation procedure.

\subsection{RH uncertainty}

For a well-calibrated H-TDMA system, the largest uncertainty in the hygroscopic growth factor results from RH uncertainties in the second humidified DMA. The RH in the system is controlled by an RH control unit, containing an RH sensor in the flow line as an input and a mechanism controlling the water vapour concentration as an output. The RH in the DMA may differ from the set point, because the temperature of the DMA and the temperature measured in the RH control unit may be different, since the RH sensor is not a part of the DMA itself. DMAs consist of massive metal bodies and only slowly follow a change in the room temperature. Even in an air-conditioned laboratory, there may be fluctuations in temperature of about 1 to $2{ }^{\circ} \mathrm{C}$ over $24 \mathrm{~h}$. The hygroscopic growth measurement is conducted in the DMA and a temperature shift leads to incorrect hygroscopic growth calculations. An inadequate calibration of the RH sensor used for the control unit may also lead to similar uncertainties. In the following experiments, ammonium sulphate particles were generated and introduced into the mixing chamber.

\subsubsection{RH deviation}

To investigate and intercompare the $\mathrm{RH}$ uncertainty and the RH stability of the different H-TDMA systems, they were operated at $90 \% \mathrm{RH}$ selecting initial dry particle sizes of $D p=30,50,70$ and $100 \mathrm{~nm}$. An air-conditioned laboratory stabilised the room temperature to around $22^{\circ} \mathrm{C}$. For comparison, the hygroscopic growth factors $G F$ measured at $90 \%$ $\mathrm{RH}$ were corrected for the individual dry growth factor derived from experiment 1 . Then, the relative humidity $\mathrm{RH}_{\text {calc }}$ based on the experimental hygroscopic growth of the observed ammonium sulphate particles was calculated based on data given by Tang and Munkelwitz (1994). The measured relative humidity $\mathrm{RH}_{\text {measured }}$ was determined in the $\mathrm{RH}$ control unit, hence $\mathrm{RH}_{\text {measured }}$ is different for every system. The deviation in $\mathrm{RH}$, here $\Delta \mathrm{RH}$, was calculated as follows:

$\Delta \mathrm{RH}=\mathrm{RH}_{\text {calc }}-\mathrm{RH}_{\text {measured }}$

Figure $3 \mathrm{a}$ and $\mathrm{b}$ show the $\Delta \mathrm{RH}$ for external and internal data evaluation for the individual H-TDMA systems. In addition, the hygroscopic growth factors are listed in Table 3 together with the growth of ammonium sulphate particles at 90\% RH reported by Tang and Munkelwitz (1994).

In total, a size dependent error, which is decreasing for system 1 and increasing for system 2 with ascending investigated size was observed. This tendency for system 1 and 2 was found independently of the type of evaluation except for system 2 evaluated for $D p=50 \mathrm{~nm}$.

System 1 showed higher uncertainties in growth factor than the other systems for both of the evaluations. This was due to technical problems with the temperature control of 
DMA 2. In system 1 DMA 2 was cooled slightly by circulating water around the column, however insufficient insulation of the DMA 2 enclosure caused the controlling RH sensor to be roughly $1{ }^{\circ} \mathrm{C}$ warmer than the DMA body itself. This led to a higher RH inside the DMA (where the sizing takes place) compared to the point where the RH was measured and thus the growth factor was higher than expected. At $90 \% \mathrm{RH}$, a decrease in temperature of $1{ }^{\circ} \mathrm{C}$ will increase the $\mathrm{RH}$ by $\sim 5 \%$. Additionally, system 1 conditioned the aerosol sample flow's RH to $82 \%$ and not to $90 \%$, which means the aerosol was exposed to an increasing RH inside DMA 2 (Biskos et al., 2006). This has an opposite effect to that of the temperature issue described above, causing an underestimation of the actual growth factor at the measured RH. As seen from the data, the temperature problem overwhelmed the RH offset from different sheath/sample RHs. For system 2, deviations in hygroscopic growth factors from literature values are smaller than $9 \%$ resulting in differences in $\mathrm{RH}$ at $90 \%$ up to $4.5 \% \mathrm{RH}$. Temperature fluctuations can account for some of the deviation, but this does not explain the observed decrease of ammonium sulphate growth factors with particle dry size. The reason for this behaviour could not be fully explained. For system 2, the precision of the dry size measurements showed strong size dependence, with the smallest sizes being most accurate, which is the opposite of what could be expected if the problem was related to the high voltage supply. Here, smaller sizes are more affected by uncertainties in high voltage supply calibration. When correcting the high humidity growth factors, the entire dry offset was assigned to DMA 1. However, the strong size dependence of the high humidity growth factors for system 2 indicate that there are multiple sources of errors, as e.g. only a flow problem of DMA 1 would not be visible in the high humidity measurements. We have not been able to find one single parameter that could explain the results from system 2 . Likely it is a result of multiple effects, such as temperature instability and poor flow calibration and to a minor extent poor high voltage calibration. As the flow calibration in the system is automated, it might be the case that dry growth factors changed over time and values obtained in the previous experiment 1 were no longer valid leading to the above mentioned problems. It should be noted that the size dependence of the accuracy problem strongly suggests that the main problem during experiment 2 is related to sizing, and not to RH. This is further supported by the DRH measurements discussed in Sect. 4.2.3. For systems 5 and 6 a difference in RH at $90 \%$ smaller than $1.5 \% \mathrm{RH}$ was found.

Discrepancies between the measured and the calculated $\mathrm{RH}$ were most likely due to temperature gradients in the systems and to insufficient calibrations of the RH control units except for system 2, where other additional problems must be responsible for the discrepancies observed. The high uncertainty for system 1 and 2 was revealed within the test, which shows the need for salt calibration measurements to be regularly carried out both during field and laboratory experiments. Similar results were obtained for both types of evaluation bearing in mind that each type of evaluation procedure included a correction of DMA dry sizing evaluated by the same data evaluation procedure.

\subsubsection{RH stability}

Figure $4 \mathrm{a}$ and $\mathrm{b}$ show the times series of recalculated relative humidity based on the procedure introduced in Sect. 4.2.1. Here, measurements of ammonium sulphate over a $12 \mathrm{~h}$ period at $\mathrm{RH}=90 \%$ (set point) and $D p=50 \mathrm{~nm}$ are illustrated. Unfortunately, this experiment is lacking data from systems 3 and 4 and only a few data points are available for system 5 . It can clearly be seen that all RH measurements follow a more or less constant gradient resulting in a slowly decreasing RH over time (about eight hours). A substantial change in RH occurred after a restart of most of the systems when a power failure occurred in the laboratory. External and internal data evaluations reflect observations obtained in Sect. 4.2.1 as differences from the RH set point are smaller for externally evaluated data in comparison to internally evaluated data. However, the general pattern in the RH determined during this experiment can be seen in both evaluations. This pattern in the determined RH implies that a parameter changing with time and in terms of hours is responsible for the observations. This drift in determined RH is likely not due to inaccuracies in RH control unit calibration, but rather more likely a result of temperature instability of the RH control unit or the DMA 2 body itself.

\subsubsection{DRH deviation}

The deviation of the RH within the H-TDMA systems was tested in experiment 3 by determining the deliquescence relative humidity (DRH) of ammonium sulphate. The DRH observed in hygroscopic growth was expected at about $80 \% \mathrm{RH}$ for ammonium sulphate particles with $D p=70 \mathrm{~nm}$ (Tang and Munkelwitz, 1993). In the transition zone at relative humidities near the DRH, sometimes non-deliquesced and deliquesced particles were measured simultaneously. This observation can be explained by a slightly non-homogeneous relative humidity in DMA 2 or the sample line leading to it, or by multiply charged particles with larger diameters behaving differently because of the Kelvin effect.

During this experiment, the systems were operated at $D p=70 \mathrm{~nm}$ increasing the $\mathrm{RH}$ from $75 \%$ to $85 \%$ yielding the offset in hygroscopic growth as DRH of ammonium sulphate particles. The following procedure was chosen for the internal data evaluation to obtain the DRH from the measured humidified particle number size distributions: the distributions were processed following the internal data evaluation procedure and finally one lognormal function was fitted to the humidified particle number size distributions. The following 

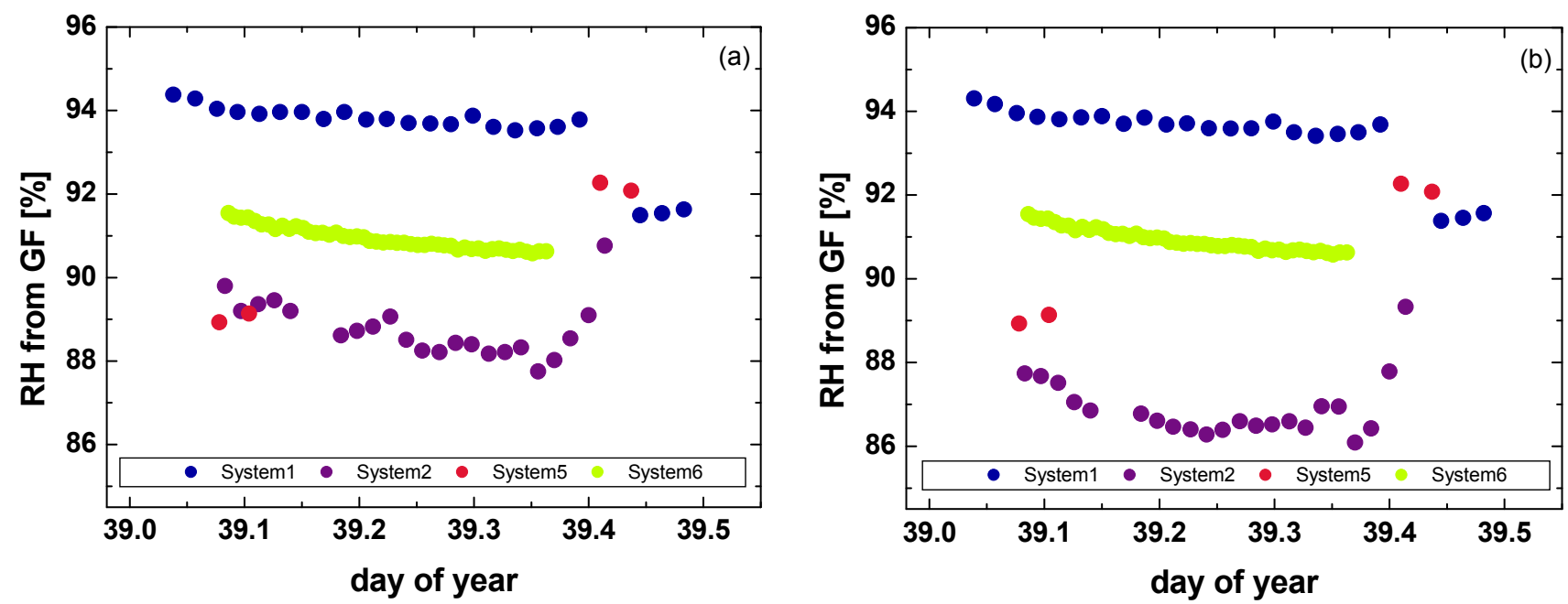

Fig. 4. Time series of (a) externally and (b) internally evaluated RH difference for all systems measured at a dry diameter of $D p=50 \mathrm{~nm}$. The set point during this experiment was $\mathrm{RH}=90 \%$.

four parameter exponential equation was fitted to the $\mathrm{RH}$ dependent growth curve.

$G F=G F_{\max }-\left\{\frac{G F_{\max }-G F_{\min }}{1+\exp [(\mathrm{RH}-\mathrm{DRH}) / S]}\right\}$

$G F_{\max }$ is the maximum $G F$ and $G F_{\min }$ is the minimum $G F$ in the S-curve in Fig. 5, DRH is the relative humidity in the inflexion point and $S$ presents the slope of the $S$-curve. The shape of this $S$-curve in Eq. (3) and the four parameters are displayed in Fig. 5. To determine the parameters $G F_{\max }, G F_{\min }, \mathrm{DRH}$, and $S$, reasonable starting parameters were chosen. Afterwards, the difference of the square from the measured $G F$ and calculated $G F$ was determined and using the residuum of the sum of squares, the best parameters were obtained. The DRH values of ammonium sulphate particles derived during experiment 3 are listed in Table 3. For a better illustration, the difference in DRH, $\triangle \mathrm{DRH}$, was calculated as follows:

$\Delta \mathrm{DRH}=\mathrm{DRH}_{\text {literature }}($ here $=80 \%)-\mathrm{DRH}_{\text {measured }}$

For the external data evaluation, the $\mathrm{DRH}_{\text {measured }}$ was obtained by the external routines. Figure $6 \mathrm{a}$ and $\mathrm{b}$ show the differences in DRH, labelled $\Delta$ DRH, calculated for the individual systems based on both, external and internal data evaluation. Based on the individual set up of the H-TDMA systems and problems listed in Sect. 4.2.1, the $\mathrm{DRH}_{\text {measured }}$ was observed at different values suggesting that the individual systems were not operating exactly at the RH set point. However, calculations for both types of evaluation resulted in similar values for individual systems.

Three out of five systems were close together and determined the DRH from literature of ammonium sulphate particles within less than $1.3 \% \mathrm{RH}$, namely system 2,5 , and 6 .

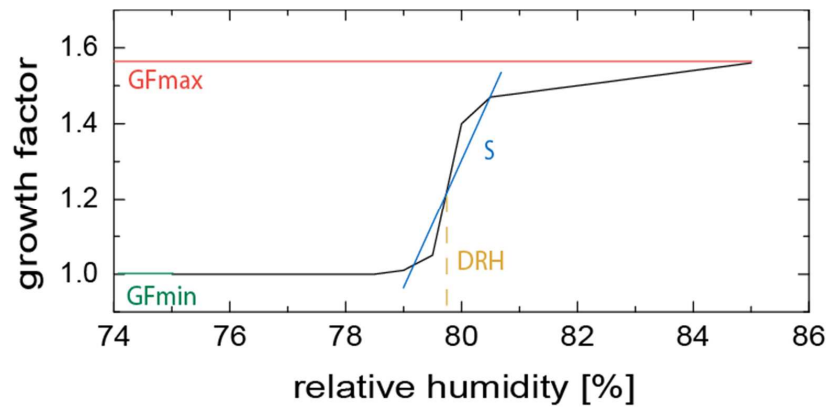

Fig. 5. Schematic of the determination of the DRH (deliquescence relative humidity) using the internal data evaluation procedure. The blue line represents the mean slope of the S-curve fitted to the data.

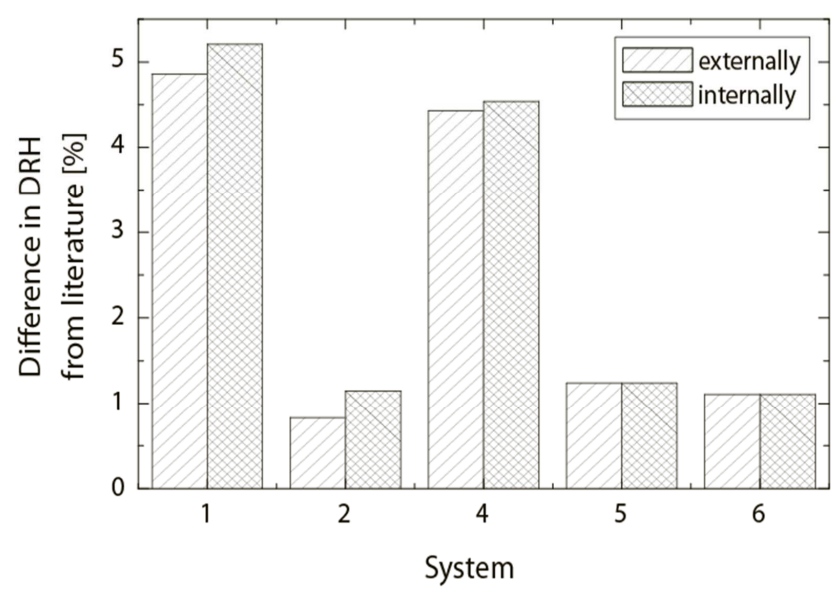

Fig. 6. Externally and internally evaluated DRH for all systems measured at a dry size of $D p=70 \mathrm{~nm}$. 
The high $\Delta$ DRH determined for system 1 and system 4 (between 4 and 5\%) can be explained by technical problems stated above and this deviation was observed also during experiment 2 (see Sect. 4.2.1). In general, an underestimation in DRH was observed for all systems, which is most unlikely to be due to a contamination of the salt solution, as system 5 and system 6 determined the DRH within about $1 \%$ and revealed good results during experiment 2 . System 2 showed also an underestimation in DRH, which is quite in opposite to its overestimation in RH during experiment 2. This indicates that the inaccuracy in experiment 3 could be attributed to typical inaccuracies in temperature and $\mathrm{RH}$ as for other systems and not to a number of problems as listed during experiment 2.

\section{Special remarks}

A dependency of DRH on size for $\sim$ sub- $100 \mathrm{~nm}$ particles has been reported by Topping et al. (2005) using direct minimisation of the free energy in the system explicitly accounting for the Kelvin effect through the inclusion of surface free energy. Such an effect was not observed by Hämeri et al. (2000) and Biskos et al. (2006) for particles smaller than $100 \mathrm{~nm}$ in diameter.

System 1 operated with a constant $8 \%$ RH difference between sheath and aerosol flows, which resulted in a slight overestimation during the DRH measurements, as the point of deliquescence occurred inside DMA 2 as described by Biskos et al. (2006) for instruments, which operate with a lower sample RH. The large underestimation of the measured DRH compared to the literature value is again attributed to the temperature variation between RH control unit and DMA 2 as discussed in Sect. 4.2.1. In this case, the temperature effect overwhelmed the effect of different sheath and aerosol flow RHs, which would most probably cause a DRH overestimation of only about $1 \%$.

System 2 showed a negative offset with respect to RH when comparing the measured growth factors with literature values. However, the DRH was shifted the other way by about $1 \%$. We believe that the problem with system 2 during experiment 2 was not due to $\mathrm{RH}$, but rather more to the sizing of the particles, most likely connected to a problem with flow in this individual case. Looking at the ammonium sulphate growth factors, particles at $D p=30 \mathrm{~nm}$ agree well with literature values from Tang and Munkelwitz (1994) and Potukuchi and Wexler (1995) but as dry size increases, the growth factor decreased, the reverse of what can be expected due to the Kelvin effect.

\section{Recommendations}

We strongly recommend thermal insulation of the RH control unit as well as the DMA 2 body itself. An exact temperature measurement as close as possible to the inner housing of the DMA 2 (sensors could be attached to or better built in the wall of the outer DMA housing) and an exact temperature measurement at the RH control unit provide the possibility of calculating the RH inside DMA 2. Deviations between the RH set point and the RH inside DMA 2 based on temperature differences can thus be considered and be corrected for.

All relative humidity sensors within H-TDMA systems should be calibrated by means of a dew point sensor or saturated salt solutions at regular intervals. We propose performing this calibration once a year and at least once when the instrument is set up for a field or laboratory study. DMA columns and the conditioning sections should be kept clean, especially from semi-volatile contamination as such contamination can influence the proceeding measurements. This recommendation is particularly important after investigations when extremely high number concentrations have been sampled by the instrument.

In addition, the automated generation of salt particles with known theoretical growth in combination with their hygroscopic growth measurement can be used to obtain the real RH inside DMA 2 at regular intervals. This procedure can be supported by DRH measurements using different salt solutions, e.g. sodium chloride, ammonium sulphate, and potassium chloride to cover the RH range from 74 up to $86 \%$. The DRH measurement gives a clear measurement of whether the system is operating at the set point of RH or not and if the sample RH is the same as the RH in DMA 2. These two procedures will assure the data quality of H-TDMA systems in terms of RH uncertainty and temperature instability which cause the greatest uncertainties in hygroscopic growth factor determination. A supplementary measurement of humidograms of e.g. ammonium sulphate particles assures the correct functioning of the H-TDMA system in its operational RH range. Similar recommendations are reported by Duplissy et al. (2009), who investigated the performance of several different H-TDMA systems when determining ammonium sulphate humidograms.

\subsection{Determination of number fractions}

The number fraction of individual hygroscopic growth groups is an additional important parameter provided by $\mathrm{H}-$ TDMA measurements as, in most cases, external particle mixtures are present in the atmosphere (Swietlicki et al., 2008). The H-TDMA system is the only instrument, which provides an online method of determining the hygroscopic mixing state. Thus we performed an experiment to intercompare the H-TDMA instruments with respect to their accuracy of determination of number fractions in case of external mixtures. This experiment focused on the ability of the different instruments to distinguish qualitatively between different hygroscopic growth groups and to quantitatively determine the number fractions of these groups for intercomparison. 


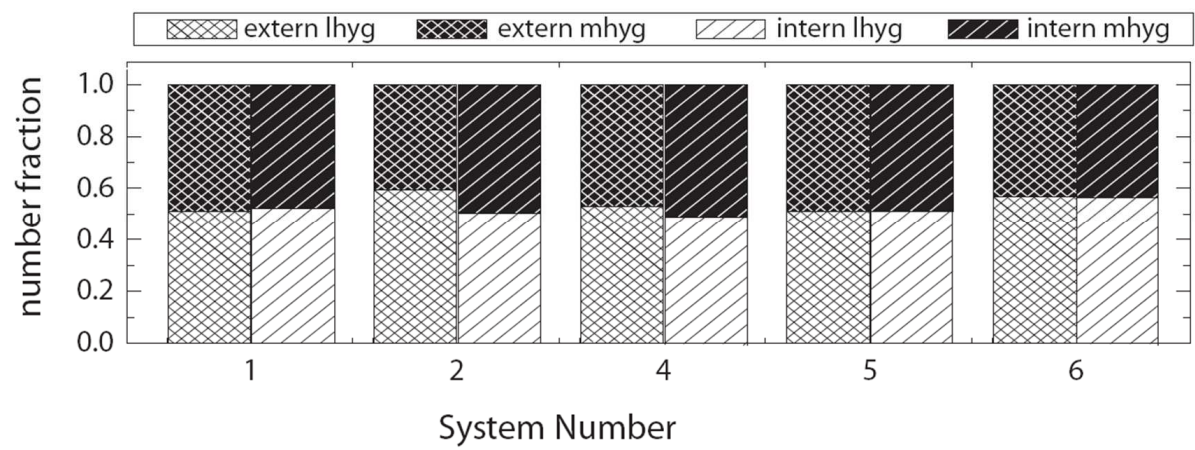

Fig. 7. Externally and internally evaluated mean number fractions of less (lhyg) and more (mhyg) hygroscopic particles of all systems measured at a dry diameter $D p=50 \mathrm{~nm}$ and at $\mathrm{RH}=85 \%$.

\subsubsection{Qualitative separation of different hygroscopic growth groups at varying $\mathrm{RH}$}

Within experiment 4, an externally mixed aerosol was generated by mixing two particle groups with different hygroscopic properties. Ammonium sulphate and soot particles were produced using two TSI-type atomisers.

The H-TDMA systems were operated at an initial dry diameter of $D p=50 \mathrm{~nm}$ at humidified conditions of (1) $\mathrm{RH}=75 \%$ and (2) $\mathrm{RH}=85 \%$. The two set points were chosen to operate the systems at one point slightly lower and one point slightly larger than the DRH point of pure ammonium sulphate particles. It was a general goal to see if the systems could qualitatively distinguish between particles of different chemical composition. As a general result, all $\mathrm{H}$ TDMA instruments only observed one single particle group at (1) $\mathrm{RH}=75 \%$. Growth factors were close to 1 indicating that ammonium sulphate particles were not in solution yet as theoretically expected. After a change of the conditioning set point at (2) $\mathrm{RH}=85 \%$, a less hygroscopic particle mode was measured by all H-TDMA instruments assuming a mixture of soot and ammonium sulphate as chemical composition. This particle mode was accompanied by a second more hygroscopic particle fraction with growth factors close to those of ammonium sulphate. It is expected that coagulation processes caused the loss of pure soot and pure ammonium sulphate particles in the mixing chamber. Thus, only chemically mixed particles were sampled. In any case all systems observed the deliquescence of ammonium sulphate being at least one compound of the observed aerosol.

The number fractions $N F_{i}$ of the observed hygroscopic growth groups can be calculated dividing the mode number concentration by the total number concentration of all modes following Eq. (5).

$N F_{i}=\frac{N_{i}}{\sum_{i=1}^{n} N_{i}}$

The number concentration of each individual hygroscopic growth group can be derived from the lognormal fit to the measured humidified size distribution $(\mathrm{d} N / \mathrm{d} \log D p)$ after applying the external/internal data evaluation procedure to the data.

Figure 7 shows the consistency of the derived number fractions (mean values) during the operation of the H-TDMA systems at $\mathrm{RH}=85 \%$. For the external data evaluation differences up to $\pm 8 \%$ ( $\pm 7 \%$ internal data evaluation) in calculated number fraction were observed. The external and internal data evaluations showed relative differences of at most $\pm 9 \%$ in determination of less or more hygroscopic fractions for individual systems. It has to be stated, that these results are based on mean values. The differences in observed values show that even if qualitatively the instruments could distinguish between different particle groups, the quantitative values for the determined number fractions differed depending on the instrument as well as on the data evaluation procedure used.

\subsubsection{Quantitative determination of number fractions}

Within experiment 5 , the same set up as for experiment 4 was chosen (see Sect. 4.3.1). The H-TDMA systems were operated at initial dry sizes of $D p=30,50,70,100 \mathrm{~nm}$ at $90 \% \mathrm{RH}$. In general, for all systems, an external particle mixture yielding two dominant different hygroscopic growth groups was observed as expected from experiment 4. Due to unknown reasons, a nearly hydrophobic particle group was also observed sometimes and only for some of the investigated particle diameters for individual instruments. This might be due to a small variation in the concentration of the individual particle groups produced by the atomisers and thus resulting in varying coagulation probabilities. It is also possible, that this mode was produced by residues dissolved in the water itself. This group only appeared as an extremely small number fraction. The humidified number size distributions measured in the second DMA were divided into one less hygroscopic particle group $(G F=1.2-1.5)$ and one more hygroscopic particle group $(G F>1.5)$ with hygroscopic growth factors close to those of pure ammonium sulphate. As stated above, the appearance of these two particle groups was most likely based 

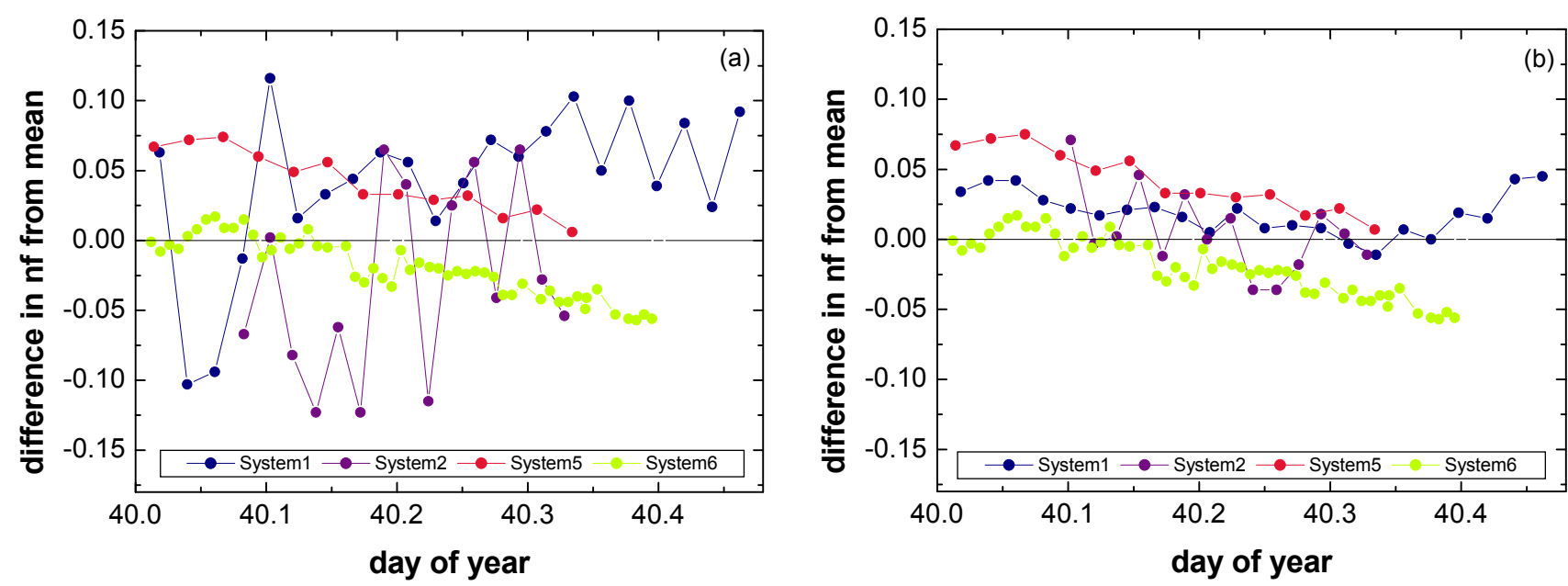

Fig. 8. Time series of (a) externally and (b) internally evaluated difference in number fraction from the mean value of less hygroscopic and more hygroscopic particles measured at a dry diameter of $\mathrm{Dp}=50 \mathrm{~nm}$ and at $\mathrm{RH}=90 \%$.

on coagulation processes causing a loss of pure soot and pure ammonium sulphate particles in the mixing chamber.

In Figure $8 \mathrm{a}$ and $\mathrm{b}$, time series of externally and internally determined number fractions derived from experiment 5 are presented for all H-TDMA systems and for an initial particle size of $D p=50 \mathrm{~nm}$. Figure $8 \mathrm{a}$ and $\mathrm{b}$ show the relative difference in the determined number fractions with respect to the mean number fraction calculated from all instruments for the internal and external evaluation routine, respectively. This illustration was chosen, because a change in partitioning between the less hygroscopic and more hygroscopic particle fractions during the experiment may have taken place. Additionally, the results from this experiment are summarised in Table 3. The internally evaluated data showed a much smaller variation over time for all instruments. Absolute deviations from the mean value are approximately $+12 /-13 \%$ for externally evaluated data including high fluctuations over time. For internally evaluated data these differences are only up to $+8 /-6 \%$ with smooth fluctuations. We assume that the small differences for internally evaluated data are due to the standardised method for the number fraction calculation. Especially, inadequate fitting routines can lead to uncertainties in the determination of number concentrations in lognormal size distributions.

\section{Recommendations}

We strongly recommend recalculating the raw H-TDMA data using at least a scheme to retrieve the $\mathrm{d} N / \mathrm{d} \log D p$ distribution using the ideal transfer function of DMA 2, which is available for every DMA. This correction is necessary for a mathematically correct determination of the number fraction of particles assigned to a single hygroscopic growth group as the raw data do not represent the real number fraction of particles in individual modes. Higher accuracy is achieved, when the individual, experimentally derived transfer functions are used for the recalculation. Unfortunately, this information is not always available for the individual DMA and requires a special calibration configuration (Birmili et al., 1997).

Since TDMA measurements do not provide information about the number of larger particles as those selected in DMA 1, a multiple charge correction is not possible based on TDMA data only. A data evaluation procedure should be able to correct for individual CPC efficiency functions, DMA diffusion losses, and system-dependent particle losses. As these parameters are size-dependent they may have significant influence on the obtained humidified particle number size distributions in the second DMA and therewith on calculated number fractions of individual hygroscopic particle groups.

\section{Summary}

Six H-TDMA systems were compared within a workshop in terms of sizing as function of particle diameter, $\mathrm{RH}$ uncertainty and stability, and determination of number fractions of externally mixed particles. The post-processing of the data was carried out with the individual data evaluation procedures (external data evaluation procedure) and with a common data evaluation procedure (internal data evaluation procedure) for comparison.

Sizing uncertainties as a function of particle diameter were found in the range of $0.2 \%$ to $4.2 \%$ depending on the individual instrument. We recommend characterising the sizing uncertainty of the H-TDMA before any study. The growth factors (measured at dry conditions) can then be used in the data processing to correct the measured hygroscopic growth factors. 
A comparison in RH uncertainty and RH stability showed that poor temperature stabilization of the RH control unit and of the DMA 2 (when humidified) can lead to substantial uncertainties in determination of hygroscopic growth factors. The difference between the measured value in the RH control unit (sometimes slightly differing from the set point of $\mathrm{RH}=90 \%$ ) and the calculated RH based on growth factors of ammonium sulphate was at most $4.5 \%$ in RH. The DRH value of ammonium sulphate particles was underestimated by up to $4.7 \%$ RH in a comparison of five out of the six investigated H-TDMA instruments. We recommend performing a sufficient calibration of the RH sensors before field and laboratory studies. It is also recommended that the temperature gradient between the RH control unit and DMA 2 is continuously monitored. In addition, we propose the recalibration of $\mathrm{RH}$ by the measurement of salt solutions with known hygroscopic growth as a routine at regular intervals during operation. Similar recommendations are reported by Duplissy et al. (2009) stating that temperature instabilities within the instrument are the most important parameter affecting the certainty of the hygroscopic growth factor measurement.

A comparison of number fractions of a mixture of ammonium sulphate and soot particles using different evaluation routines showed significant discrepancies. Number fractions varied by $+12 /-13 \%$ (external data evaluation) and $+8 /-6 \%$ (internal data evaluation) from the mean value. The fluctuation in determination of number fractions by some H-TDMA systems was quite high, which only partly can be explained by a probable change of partitioning between less and more hygroscopic particle fractions during this experiment. Furthermore, we recommend a more accurate evaluation in real particle number concentration assigned to individual hygroscopic growth groups. This can be achieved by taking into account losses and efficiency functions of the individual parts of the system as well as using a robust data fitting routine. In order to avoid the application of individual data fitting routines, we suggest the use of the TDMAinv algorithm provided by Gysel et al. (2009). As a large advantage, this algorithm provides the possibility to obtain number fractions for selected growth factor ranges. This procedure avoids any uncertainties in determination of number fractions based on different fitting routines, but rather more calculates the integral in a defined size range of the humidified size distribution treating different humidified size distributions equally.

In general, the differences between externally evaluated and internally evaluated data were very small for measurements of particle sizing and RH uncertainty with some single exceptions. However, substantial differences were observed for determined number fractions in case of external mixtures assuming that inadequate fitting routines were the reason for this finding.
Acknowledgements. The H-TDMA calibration and intercomparison workshop held at the WMO-GAW World Calibration Centre for Aerosol Physics, Leipzig, Germany, was supported by the EU-projects ACCENT (GOCE-CT-2004-505337), EUSAAR (RII3-CT-2006-14 026140) and by the German Federal Environment Agency (FKZ: 35101 046: GAW World Calibration Centre).

Edited by: J.-P. Putaud

\section{References}

Birmili, W., Stratmann, F., Wiedensohler, A., Covert, D. S., Russell, L. M., and Berg, O.: Determination of differential mobility analyzer transfer functions using identical instruments in series, Aerosol Sci. Tech., 27(2), 215-223, 1997.

Biskos, G., Paulsen, D., Russell, L. M., Buseck, P. R., and Martin, S. T.: Prompt deliquescence and efflorescence of aerosol nanoparticles, Atmos. Chem. Phys., 6, 4633-4642, doi:10.5194/acp-64633-2006, 2006.

Cheng, Y. F., Heintzenberg, J., Wehner, B., Wu, Z. J., Su, H., Hu, M., and Mao, J. T.: Traffic restrictions in Beijing during the Sino-African Summit 2006: aerosol size distribution and visibility compared to long-term in situ observations, Atmos. Chem. Phys., 8, 7583-7594, doi:10.5194/acp-8-7583-2008, 2008.

Cubison, M. J., Coe, H., and Gysel, M.: A modified hygroscopic tandem DMA and a data retrieval method based on optimal estimation, J. Aerosol Sci., 36, 846-865, 2005.

Duplissy, J., Gysel, M., Sjogren, S., Meyer, N., Good, N., Kammermann, L., Michaud, V., Weigel, R., Martins dos Santos, S., Gruening, C., Villani, P., Laj, P., Sellegri, K., Metzger, A., McFiggans, G. B., Wehrle, G., Richter, R., Dommen, J., Ristovski, Z., Baltensperger, U., and Weingartner, E.: Intercomparison study of six HTDMAs: results and recommendations, Atmos. Meas. Tech., 2, 363-378, doi:10.5194/amt-2-363-2009, 2009.

Gysel, M., McFiggans, G., and Coe, H.: Inversion of Tandem Differential Mobility Analyser (TDMA) measurements, J. Aerosol Sci., 40, 134-151, 2009.

Hämeri, K., Väkevä, M., Hansson, H.-C., and Laaksonen, A.: Hygroscopic Growth of Ultrafine Ammonium Sulphate Aerosol Measured Using an Ultrafine Tandem Differential Mobility Analyser, J. Geophys. Res., 105, 22231-22242, 2000.

Hennig, T., Massling, A., Brechtel, F. J., and Wiedensohler, A.: A tandem DMA for highly temperature-stabilized hygroscopic particle growth measurements between $90 \%$ and $98 \%$ relative humidity, J. Aerosol Sci., 1, 1210-1223, 2005.

IPCC: Climate change 2007, edited by: Pachauri, R. K. and Reisinger, A., Geneva, Switzerland, 104 pp., 2007.

Johnson, G. R., Ristovski, Z. D., D’Anna, B., and Morawska, L.: Hygroscopic behavior of partially volatilized coastal marine aerosols using the volatilization and humidification tandem differential mobility analyzer technique, J. Geophys. Res.-Atmos., 110(D20), D20203, doi:10.1029/2004JD005657, 2005.

Kandler, K. and Schütz, L.: Climatology of the average watersoluble volume fraction of atmospheric aerosol, Atmos. Res., 83(1), 77-92, 2007.

Kaufmann, Y. J., Tanre, D., and Boucher, O.: A satellite view of aerosols in the climate system, Nature, 419, 215-223, 2002. 
Liu, B. Y. H., Pui, D. Y. H., Whitby, K. T., Kittelson, D. B., Kousaka, Y., and McKenzie, R. L.: The aerosol mobility chromatograph: a new detector for sulfuric acid aerosols, Atmos. Environ., 12, 99-104, 1978.

Maßling, A., Wiedensohler, A., Busch, B., Neusüß, C., Quinn, P., Bates, T., and Covert, D.: Hygroscopic properties of different aerosol types over the Atlantic and Indian Oceans, Atmos. Chem. Phys., 3, 1377-1397, doi:10.5194/acp-3-1377-2003, 2003.

Potukuchi, S. and Wexler, A. S.: Identifying solid-aqueous phase transitions in atmospheric aerosols: I. Neutral-acidity solutions, Atmos. Environ., 29, 1663-1676, 1995.

Rader, D. J. and McMurry, P. H.: Application of the Tandem Differential Mobility Analyzer to Studies of Droplet Growth or Evaporation, J. Aerosol Sci., 17, 771-787, 1986.

Ramanathan, V., Crutzen, P. J., Kiehl, J. T., and Rosenfeld, D.: Atmosphere - Aerosols, climate, and the hydrological cycle, Science, 294, 2119-2124, 2001.

Stolzenburg, M. R. and McMurry, P. H.: TDMAFIT user's manual, University of Minnesota, Department of Mechanical Engineering, Particle Technology Laboratory, Minneapolis, 1-61, 1988.

Swietlicki, E., Hansson, H.-C., Hämeri, K., Massling, A., Petäjä, T., Tunved, P., Weingartner, E., Baltensperger, U., McMurry, P. H., McFiggans, G., Svenningsson, B., Rissler, J., Wiedensohler, A., and Kulmala, M.: Hygroscopic properties of sub-micrometer atmospheric aerosol particles measured with H-TDMA instruments in various environments - a review, Tellus, 60(3), 432469, 2008.
Tang, I. N. and Munkelwitz, H. R.: Composition and temperature dependence of the deliquescence properties of hygroscopic aerosols, Atmos. Environ., 27A, 467-473, 1993.

Tang, I. N. and Munkelwitz, H. R.: Water activities, densities, and refractive indices of aqueous sulfate and sodium nitrate droplets of atmospheric importance, J. Geophys. Res., 99, 18801-18808, 1994.

Topping, D. O., McFiggans, G. B., and Coe, H.: A curved multicomponent aerosol hygroscopicity model framework: Part 1 - Inorganic compounds, Atmos. Chem. Phys., 5, 1205-1222, doi:10.5194/acp-5-1205-2005, 2005.

Villani, P., Picard, D., Michaud, V., Laj, P., and Wiedensohler, A.: Design and validation of a volatility hygroscopic tandem differential mobility analyser (VHTDMA) to characterize the relationships between the thermal and hygroscopic properties of atmospheric aerosol particles, Aerosol Sci. Tech., 42, 729-741, 2008.

Voutilainen, A., Stratmann, F., and Kaipio, J. P.: A nonhomogenous regularization method for the estimation of narrow aerosol size distribution, J. Aerosol Sci., 31(12), 1433-1445, 2000.

Weingartner, E., Gysel, M., and Baltensperger, U.: Hygroscopicity of aerosol particles at low temperatures, 1 . New low-temperature H-TDMA instrument: Setup and first applications, Environ. Sci. Technol., 36, 55-62, 2002.

Zhou, J.: Hygroscopic properties of atmospheric aerosol particles in various environments, ISBN 91-7874-120-3, Doctoral dissertation at Lund University, Dep. of Nuclear Physics, Lund, Sweden, 2001. 